\title{
sciendo
}

\section{ANTIMICROBIAL SUSCEPTIBILITY OF STREPTOCOCCI MOST FREQUENTLY ISOLATED FROM CZECH DAIRY COWS WITH MASTITIS*}

\author{
Soňa Šlosárková ${ }^{1}$, Kateřina Nedbalcová1, Jaroslav Bzdil ${ }^{2}$, Petr Fleischer ${ }^{1 \bullet}$, Monika Zouharová1, \\ Stanislav Staněk ${ }^{3}$, Eva Kašná ${ }^{4}$, Alena Pechová ${ }^{1}$ \\ 'Department of Immunology, Veterinary Research Institute, Hudcova 296/70, 62100 Brno, \\ Czech Republic \\ ${ }^{2}$ Department of Special Microbiology, State Veterinary Institute Olomouc, Jakoubka ze Stříbra 1, \\ 77900 Olomouc, Czech Republic \\ ${ }^{3}$ Department of Livestock Technology and Management, \\ ${ }^{4}$ Department of Animal Genetics and Breeding, \\ Institute of Animal Science, Přátelství 815, 10400 Prague 10 - Uhříněves, Czech Republic \\ •Corresponding author: fleischer@vri.cz
}

\begin{abstract}
The aim was to investigate the antimicrobial susceptibility of most frequently isolated streptococci from Czech dairy herds. A total of 3,719 quarter milk samples were collected and cultivated between January 2017 and June 2018 from cows with clinical or subclinical mastitis from 112 farms. Only one isolate of each species, collected from the same farm per six-month period, was included in the susceptibility testing. The susceptibilities of Streptococcus uberis (163 isolates) and $S$. dysgalactiae (25 isolates) to 10 antimicrobials (penicillin - PEN, amoxicillin/clavulanic acid - AMC, ceftiofur - EFT, clindamycin - CLI, gentamicin - GEN, streptomycin - STR, trimethoprim/sulfamethoxazole - SXT, enrofloxacin - ENR, tetracycline - TET, rifampicin - RIF) from 9 groups were determined by measuring their minimum inhibitory concentrations. The percentages of resistant $S$. uberis isolates to the antimicrobials were as follows: TET (63.2\%), STR (52.1\%), CLI (30.1\%), and RIF (2.5\%). Intermediate susceptibility was found to RIF (63.2\%), PEN (35\%), ENR $(\mathbf{2 . 5} \%)$, EFT (1.8\%), and AMC (1.2\%). All the $S$. uberis isolates were susceptible to GEN and SXT $(\mathbf{1 0 0} \%)$. However, only $\mathbf{6 . 7 \%}$ of $S$. uberis isolates were susceptible to all tested antimicrobials, and $38.7 \%$ of isolates were multidrug resistant $(\geq 3$ groups of antimicrobials). All the $S$. dysgalactiae isolates were susceptible to PEN, AMC, EFT, GEN, SXT, and ENR (100\%). Resistant S. dysgalactiae isolates were found to TET (60\%), STR (28\%), CLI (12\%), and intermediate to TET (24\%) and RIF (20\%). Sixteen percent of $S$. dysgalactiae isolates were multidrug resistant. The relatively high occurrence of (multiple) resistance, relative to mastitis pathogens, highlights the importance of monitoring this condition in dairy herds.
\end{abstract}

Key words: cattle, $S$. uberis, $S$. dysgalactiae, MIC, multiple resistance

*This study was supported by the Ministry of Agriculture of the Czech Republic, projects no. QJ1510217 and QJ1910320 and the Ministry of Education, Youth and Sports of the Czech Republic (LO1218). 
In dairy herds, mastitis is one of the most frequently diagnosed diseases and causes significant losses to farmers (Halasa et al., 2007). The etiology of infectious mastitis involves numerous organisms as diverse as bacteria, mycoplasma, yeasts, and algae, but streptococci, staphylococci, and coliform bacteria (Escherichia coli) are considered to be the major mastitis pathogens (Watts, 1988; Bradley, 2002). Among gram-positive organisms, environmental streptococci, and coagulase-negative staphylococci (CNS) are currently the most prevalent pathogens recovered from clinical cases of mastitis in the USA, New Zealand, United Kingdom, and Switzerland (Bradley, 2002; McDougall et al., 2007; Oliveira et al., 2013; Rüegsegger et al., 2014). Similarly, in the Czech Republic, Bzdil (2012) showed that the most common mastitis pathogen was Streptococcus (S.) uberis (22.1\%).

Mastitis is the most common reason for the use of antimicrobials in dairy cows, and they are an important part of mastitis treatment (de Jong et al., 2018). The antimicrobials used to treat intramammary infections in cows are similar across the world; however, the frequency of use differs between countries (Oliver and Murinda, 2012). In Europe (Belgium, Germany, France, Spain, Sweden, and the UK) the $\beta$-lactams (29-84\%; 84\% = Sweden) are commonly used, including penicillin, aminopenicillins (including combinations with clavulanic acid), isoxazolyl penicillins, and cephalosporins, particularly the 3 rd and 4th generations. To a lesser extent, aminoglycosides and macrolides are also used (De Briyne et al., 2014). In the Czech Republic, the whole group of beta-lactams, e.g., amoxicillin in combination with a beta-lactamase inhibitor (e.g., clavulanic acid) are commonly used in the treatment of mastitis, together with 3rd and 4th generation cephalosporins (Nedbalcova et al., 2014).

Ideally, when deciding on an antimicrobial treatment for mastitis, the antimicrobial susceptibility of the udder pathogens should be known. However, since mastitis therapy is commonly initiated before pathogen susceptibility testing, monitoring antimicrobial resistance trends over time is very important (de Jong et al., 2018).

There are many non-European (McDougall et al., 2014; Ruegg et al., 2015; Cameron et al., 2016), European (Bengtsson et al., 2009; Burmańczuk et al., 2016; Crestani et al., 2016) and pan-European studies (Thomas et al., 2015; de Jong et al., 2018) dealing with the susceptibility of mastitis pathogens to antimicrobials. Over the past decade, several national programs have monitored the susceptibility of important veterinary pathogens to antimicrobials, e.g., Germany - GERMAP (2014) and Sweden - SVARM (SVA, 2018). A similar, but voluntary, national program has been functioning in the Czech Republic since 2015 (SVS ČR, 2017). The most disturbing fact revealed by the program was that $60.2 \%$ of mastitis pathogens in the Czech Republic carried at least one antibiotic resistance gene and $44.6 \%$ were multidrug-resistant (Pyatov et al., 2017). In the Czech Republic, only a few extensive studies of antimicrobial susceptibility of mastitis pathogens have been performed up to the present time.

The objective of this study was to investigate antimicrobial susceptibility of the most frequently isolated streptococci originating from Czech dairy cows with mastitis. 


\section{Material and methods}

\section{Milk samples}

A total of 3,719 quarter milk samples were collected from cows with clinical or subclinical mastitis. The samples were delivered on a voluntary basis by local veterinarians from 112 farms in the eastern part of the Czech Republic, between January 1st, 2017 and June 30th, 2018, to pick-up points of the State Veterinary Institute, Olomouc, Czech Republic. The samples were transported in cool boxes at $4{ }^{\circ} \mathrm{C}$.

\section{Isolation and identification of bacteria}

The samples were subjected to conventional bacteriology (cultivation, isolation of the agents and their identification). All milk samples were inoculated onto Meat Peptone Blood Agar (MPBA) (Trios Ltd., Prague, Czech Republic) and incubated aerobically at $37 \pm 1{ }^{\circ} \mathrm{C}$ for $42-48$ hours. In parallel, the same milk samples were placed in culture tubes with MPBA and incubated at $37 \pm 1^{\circ} \mathrm{C}$ for $18-24$ hours. Subsequently, the incubated milk samples were inoculated onto Edward's Agar (Trios Ltd., Prague, Czech Republic). The inoculated Edward's Agar plates were incubated at $37 \pm 1{ }^{\circ} \mathrm{C}$ for another $18-24$ hours (Bzdil, 2004). On plates with mixed bacterial cultures, the most frequent colony forming agent was regarded as the major pathogen.

Suspicious colonies of streptococci were isolated. The isolated strains were subsequently confirmed using phenotypic molecular mass spectrometry, MALDI TOF MS, based on proteomics analyses, and MALDI Biotyper software (Bruker Daltonik GmbH, Bremen, Germany) (Štromerová, 2013).

\section{Antimicrobial susceptibility testing}

Selected isolates of the most frequently isolated streptococci were tested for susceptibility to a variety of antimicrobial agents. No more than one isolate of each species collected from the same farm per six-month period was included in antimicrobial susceptibility testing (AST). Isolates from animals that had been treated with antimicrobials during the two weeks prior to sampling were not included in the study. The minimum inhibitory concentrations (MICs) of antimicrobials were determined for 163 isolates of $S$. uberis and 25 isolates of $S$. dysgalactiae.

The resistance of isolates to antimicrobials was tested using a standardized microdilution method for determining MICs and followed international standardized methodologies. The MIC sets were prepared according to the method described in Clinical Laboratory Standard Institute (CLSI) document VET01-A4 (CLSI, 2013) and interpretation of the results was performed by clinical breakpoints published in CLSI supplements VET01S and VET08 (CLSI, 2015; CLSI, 2018), European Committee on Antimicrobial Susceptibility Testing - Breakpoint tables for bacteria (EUCAST, 2018) and Comité de l'Antibiogramme de la Société Francaise de Microbiologie - Recommandations vétérinaires 2018 (CA-SFM, 2018). The testing was performed using kits manufactured in the laboratory of the authors at the Veterinary Research Institute in Brno. The kits were manufactured using CLSI standard methods. According to CLSI documents, special microdilution trays were prepared. 
These trays, with twofold dilutions of tested antimicrobial agents (Discovery Fine Chemicals, UK) in Mueller-Hinton Broth (Becton, Dickinson and Company, USA) with 4\% Lysed Horse Blood (LabMediaServis, CR), were designed for antimicrobial susceptibility testing of veterinary pathogens and included various bacterial species. The tested antimicrobials were therefore selected from a wider spectrum of antimicrobials than those typically used in the treatment of mastitis, i.e., they included antimicrobials used to treat other bacterial diseases of farm animals; e.g., ceftiofur, a cephalosporin, was included in spite of the fact that it is not registered for the treatment of mastitis in the Czech Republic and the injectable form is not indicated for the treatment of mastitis due to its pharmacokinetic characteristics, nonetheless, it was the most frequently used cephalosporin in cattle (Nedbalcova et al., 2014). Quality control of the testing kits and the testing itself were performed using the S. pneumoniae ATCC 49619 reference strain. The tested antimicrobials and their respective concentration ranges are listed in Table 1.

Table 1. Tested antimicrobials and their concentrations

\begin{tabular}{l|c}
\hline \multicolumn{1}{c|}{ Antimicrobials } & $\begin{array}{c}\text { Tested concentrations } \\
(\mathrm{mg} / \mathrm{L})\end{array}$ \\
\hline Penicillin & $0.06-8$ \\
Amoxicillin/clavulanic acid $(2 / 1)^{\mathrm{a}}$ & $0.5-64$ \\
Ceftiofur & $0.25-32$ \\
Clindamycin & $0.125-16$ \\
Gentamicin & $2-8$ and $128-256$ \\
Streptomycin & $2-32$ and $256-1024$ \\
Trimethoprim/sulfamethoxazole $(1 / 19)^{\mathrm{b}}$ & $0.25-32$ \\
Enrofloxacin & $0.06-8$ \\
Tetracycline & $0.25-32$ \\
Rifampicin & $0.03-4$ \\
\hline
\end{tabular}

${ }^{\text {a }}$ concentrations relative to amoxicillin.

${ }^{\mathrm{b}}$ concentrations relative to trimethoprim.

The MICs values were read as the lowest concentration of an antimicrobial agent that inhibited visible bacterial growth. $\mathrm{MIC}_{50}$ and $\mathrm{MIC}_{90}$ are the lowest concentrations of antimicrobial substances, in $\mathrm{mg} / \mathrm{L}$, that inhibited the growth of $50 \%$ and $90 \%$ of isolates as determined by cumulative conversion (Schwarz et al., 2010). Since there are no interpretative AST criteria for mastitis pathogens for the majority of antimicrobials (except for ceftiofur (CLSI, 2018)), the categorizing of isolates as susceptible, intermediate, and resistant was performed according to human-derived clinical breakpoints (CLSI, 2015; CA-SFM, 2018; CLSI, 2018; EUCAST, 2018) see Table 2.

For each pathogen, the profiles of phenotypic resistances from non-susceptible (resistant and intermediate) isolates to individual antimicrobials were assembled. Based on the profiles, multidrug resistance can be evaluated. A multidrug-resistant 
isolate was defined as an isolate that was not sensitive to at least one agent in three or more antimicrobial groups (Magiorakos et al., 2011). The 10 antimicrobials used for testing represented 9 antimicrobial groups: lincosamides, aminoglycosides, sulfonamides, quinolones, tetracyclines, ansamycins; the penicillins (narrow spectrum, penicillinase sensitive), penicillins with beta-lactamase inhibitors (amoxicillin with clavulanic acid), and cephalosporins (3rd generation) were considered as three separate groups.

Table 2. Breakpoint table for Streptococcus spp.

\begin{tabular}{|c|c|c|c|c|}
\hline \multirow[t]{2}{*}{ Antimicrobials } & \multicolumn{3}{|c|}{$\begin{array}{c}\text { MIC breakpoint } \\
(\mathrm{mg} / \mathrm{L})\end{array}$} & \multirow[t]{2}{*}{ Source } \\
\hline & $\mathrm{S}$ & I & $\mathrm{R}$ & \\
\hline Penicillin (Streptococcus viridans group - S. uberis) & $\leq 0.25$ & $0.5-2$ & $\geq 4$ & EUCAST, 2018 \\
\hline Penicillin ( $\beta$-hemolytic streptococci $-S$. dysgalactiae) & $\leq 0.25$ & - & $\geq 0.5$ & EUCAST, 2018 \\
\hline Amoxicillin/clavulanic acid $(2 / 1)^{\mathrm{a}}$ & $\leq 0.5$ & $1-2$ & $\geq 4$ & CLSI, 2015 \\
\hline Ceftiofur & $\leq 2$ & 4 & $\geq 8$ & CLSI, 2018 \\
\hline Clindamycin & $\leq 0.5$ & - & $\geq 1$ & EUCAST, 2018 \\
\hline Gentamicin & $\leq 128$ & - & $\geq 256$ & CLSI, 2015 \\
\hline Streptomycin & $\leq 256$ & - & $\geq 512$ & CA-SFM, 2018 \\
\hline Trimethoprim/sulfamethoxazole $(1 / 19)^{\mathrm{b}}$ & $\leq 0.5$ & $1-2$ & $\geq 4$ & CLSI, 2018 \\
\hline Enrofloxacin & $\leq 0.5$ & $1-2$ & $\geq 4$ & CA-SFM, 2018 \\
\hline Tetracycline (Streptococcus viridans group - S. uberis) & $\leq 2$ & 4 & $\geq 8$ & EUCAST, 2018 \\
\hline Tetracycline $(\beta$-hemolytic streptococci $-S$. dysgalactiae $)$ & $\leq 1$ & 2 & $\geq 4$ & EUCAST, 2018 \\
\hline Rifampicin & $\leq 0.06$ & $0.125-0.5$ & $\geq 1$ & EUCAST, 2018 \\
\hline
\end{tabular}

\section{Results}

Potential mastitis pathogens were found in $47.1 \%$ of the milk samples, i.e., in 1,752 out of 3,719 . A total of 2,284 isolates were gram-positive $(\mathrm{G}+)$ microorganisms, of which 708 (in 19.0\% milk samples; $31.0 \%$ of $\mathrm{G}+$ isolates) were $S$. uberis, $S$. dysgalactiae, and $S$. agalactiae. Samples with no growth or contamination (massive presence of more than 4 microbial species) constituted $21.4 \%$ and $31.5 \%$ of all samples, respectively. S. uberis (648 isolates) was the most frequently isolated pathogen (in $17.4 \%$ milk samples; $28.4 \%$ of G+ isolates); S. dysgalactiae with 41 isolates $(1.1 \% ; 1.8 \%)$; and $S$. agalactiae with 19 isolates $(0.5 \% ; 0.8 \%)$, was markedly less frequent.

Distributions of MICs for individual antimicrobials and species and $\mathrm{MIC}_{50}$ and $\mathrm{MIC}_{90}$ values are shown in Tables 3 and 4. 


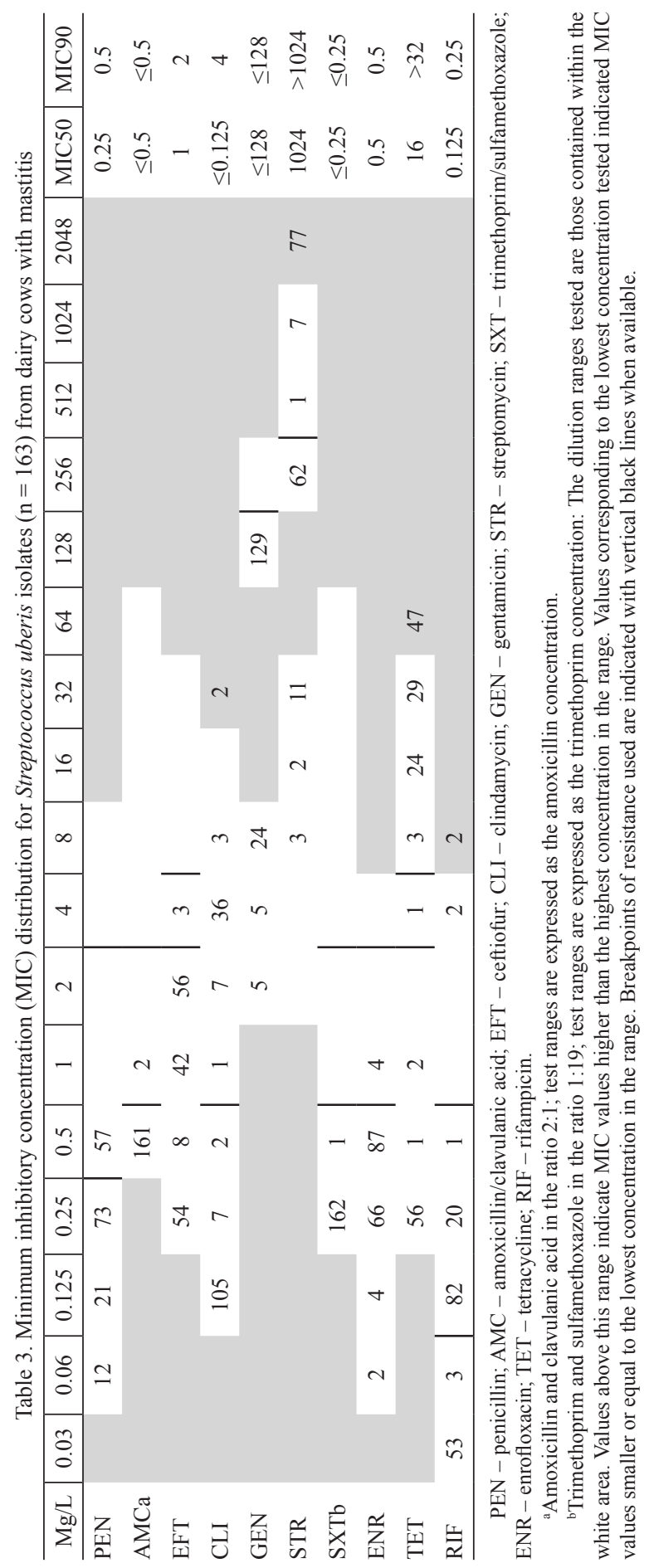




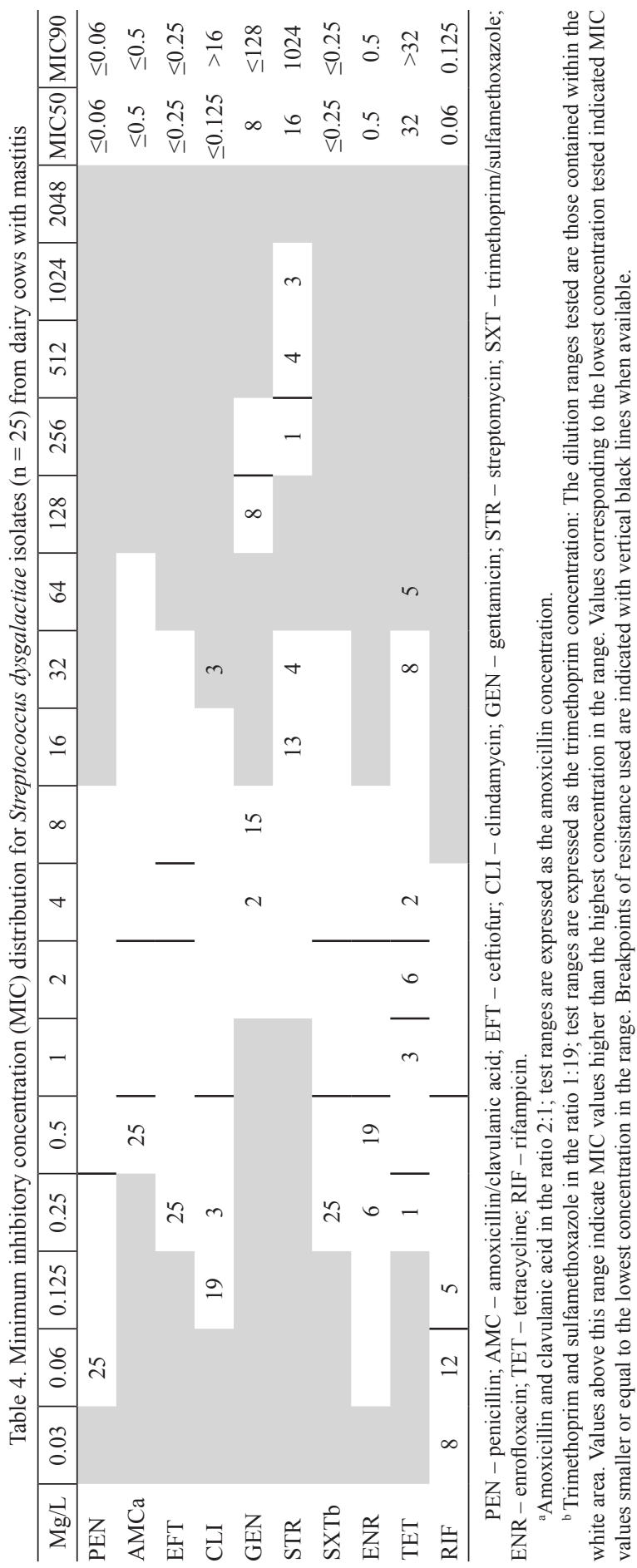


Isolates of each bacterial species were categorized as susceptible, intermediate, or resistant using clinical breakpoints (Table 2). Percentages of isolates susceptible, intermediate, or resistant to tested antimicrobials are shown in Figures 1 and 2. The profiles of phenotypic resistances are shown in Tables 5 and 6.

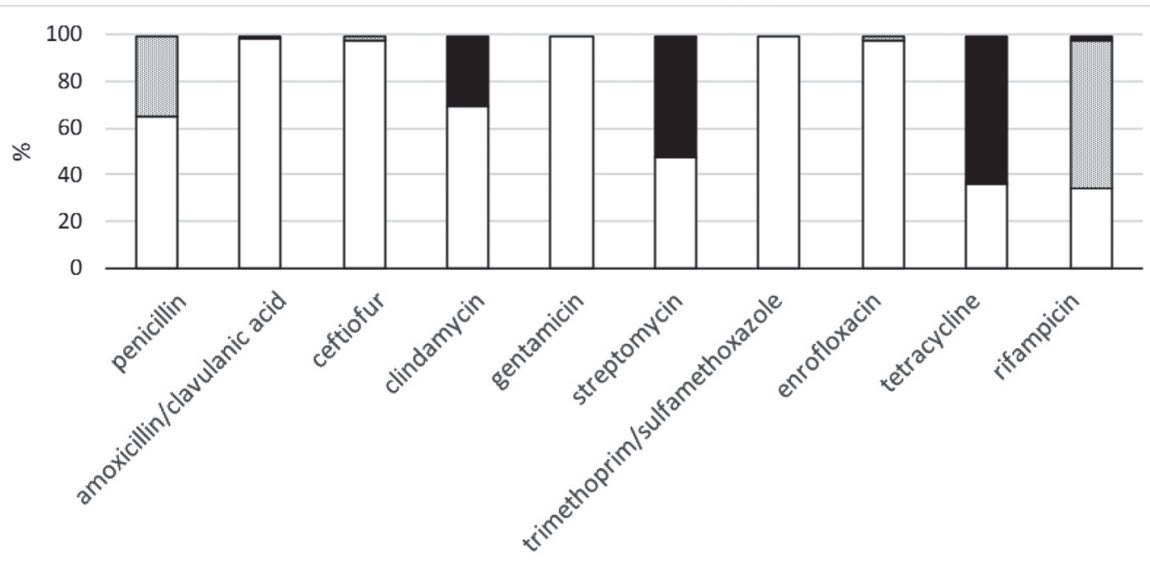

Figure 1. Percentages of $S$. uberis isolates $(n=163)$ susceptible, intermediate, or resistant to tested antimicrobials

Table 5. Resistance profiles for Streptococcus uberis isolates $(\mathrm{n}=163)$

\begin{tabular}{c|c|c|cc|c}
\hline \multicolumn{2}{c|}{$\begin{array}{c}\text { Frequency of resistance by } \\
\text { active } \\
\text { substance }\end{array}$} & $\begin{array}{c}\text { antimicrobial } \\
\text { groups }\end{array}$ & $\begin{array}{c}\text { Phenotype } \\
\text { of resistance }\end{array}$ & $\begin{array}{c}\text { Number } \\
\text { of resistant } \\
\text { isolates }\end{array}$ & $\begin{array}{c}\text { Number of multidrug-resistant } \\
\text { isolates }\end{array}$ \\
\hline 1 & 2 & 3 & & 4 & 5 \\
\hline 0 & 0 & RIF & 30 & $(18.4 \%)$ & \\
1 & 1 & TET & 12 & $(7.4 \%)$ & \\
1 & 1 & STR & 4 & $(2.5 \%)$ & \multirow{2}{*}{$100(61.3 \%)$} \\
1 & 1 & ENR & 1 & $(0.6 \%)$ & \\
1 & 1 & EFT & 1 & $(0.6 \%)$ & \\
1 & 1 & TET, RIF & 19 & $(11.7 \%)$ & \\
2 & 2 & STR, TET & 14 & $(8.6 \%)$ & \\
2 & 2 & STR, RIF & 4 & $(2.5 \%)$ & \\
2 & 2 & PEN, TET & 2 & $(1.2 \%)$ & \\
2 & 2 & CLI, RIF & 1 & $(0.6 \%)$ & \\
2 & 2 & PEN, RIF & 1 & $(0.6 \%)$ & \\
2 & 2 & & &
\end{tabular}


Table 5 - contd.

\begin{tabular}{l|l|c|c|c|c}
\hline 1 & 2 & 3 & 4 & 5 & 6 \\
\hline 3 & 3 & STR, TET, RIF & 11 & $(6.7 \%)$ & \\
3 & 3 & CLI, STR, TET & 7 & $(4.3 \%)$ & \\
3 & 3 & CLI, STR, RIF & 7 & $(4.3 \%)$ & \\
3 & 3 & ENR, TET, RIF & 1 & $(0.6 \%)$ & \\
3 & 3 & PEN, STR, TET & 1 & $(0.6 \%)$ & \\
3 & 3 & CLI, TET, RIF & 1 & $(0.6 \%)$ & $(38.7 \%)$ \\
4 & 4 & CLI, STR, TET, RIF & 25 & $(15.3 \%)$ & \\
4 & 4 & PEN, STR, TET, RIF & 1 & $(0.6 \%)$ & \\
4 & 4 & EFT, STR, TET, RIF & 1 & $(0.6 \%)$ & \\
4 & 4 & CLI, STR, ENR, TET & 1 & $(0.6 \%)$ & \\
5 & 5 & PEN, CLI, STR, TET, & 6 & $(3.7 \%)$ & \\
7 & 7 & PEN, EFT, CLI, STR, & 1 & $(0.6 \%)$ \\
& & & & \\
\end{tabular}

PEN - penicillin; EFT - ceftiofur; CLI - clindamycin; STR - streptomycin; ENR - enrofloxacin; TET tetracycline; RIF - rifampicin.

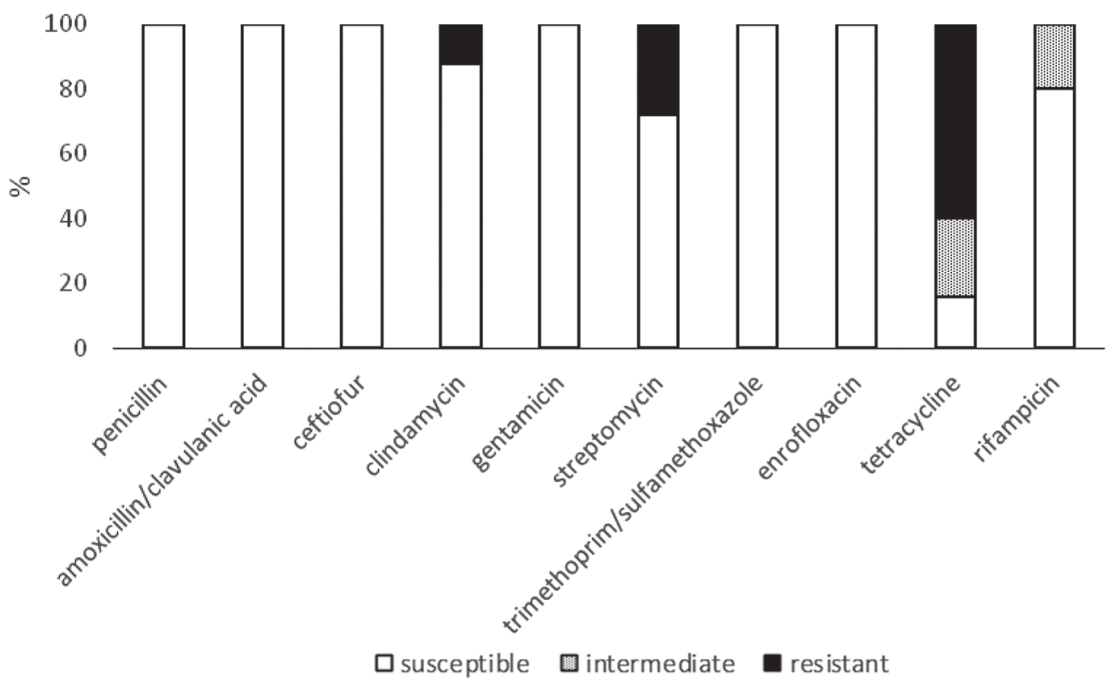

Figure 2. Percentages of $S$. dysgalactiae isolates $(n=25)$ susceptible, intermediate, or resistant to tested antimicrobials

The highest percentage of resistant $S$. uberis isolates was found to tetracycline $(63.2 \%)$, and streptomycin $(52.1 \%)$, with a significant percentage of $S$. uberis isolates also being resistant to clindamycin (30.1\%). On the other hand, all the isolates tested were susceptible to gentamicin and trimethoprim/sulfamethoxazole. Most of the tested isolates were susceptible to amoxicillin/clavulanic acid (98.8\%), ceftiofur 
$(98.2 \%)$, and enrofloxacin $(97.5 \%)$. The isolates were categorized as being intermediate relative to rifampicin $(63.2 \%)$ and penicillin $(35.0 \%)$. However, none or only a few isolates were resistant to penicillin $(0 \%)$ and rifampicin $(2.5 \%)$.

Only $11(6.7 \%)$ S. uberis isolates were found to be susceptible to all tested antimicrobials and quite a lot were multidrug resistant (63 isolates, 38.7\%). The most frequent combination of resistances was to clindamycin, streptomycin, tetracycline, and rifampicin, in $25(15.3 \%)$ isolates.

All the $S$. dysgalactiae isolates were susceptible to penicillin, amoxicillin/clavulanic acid, ceftiofur, gentamicin, trimethoprim/sulfamethoxazole, and enrofloxacin. In terms of resistance, $S$. dysgalactiae isolates were resistant to tetracycline $(60.0 \%)$, streptomycin (28.0\%), and clindamycin (12.0\%). Additionally, S. dysgalactiae isolates were categorized as intermediate relative to tetracycline $(24.0 \%)$ and rifampicin $(20.0 \%)$.

Table 6. Resistance profiles for Streptococcus dysgalactiae isolates $(\mathrm{n}=25)$

\begin{tabular}{|c|c|c|c|c|c|}
\hline \multicolumn{2}{|c|}{ Frequency of resistance by } & \multirow{2}{*}{$\begin{array}{l}\text { Phenotype } \\
\text { of resistance }\end{array}$} & \multirow{2}{*}{\multicolumn{2}{|c|}{$\begin{array}{c}\text { Number } \\
\text { of resistant isolates }\end{array}$}} & \multirow{2}{*}{$\begin{array}{c}\text { Number } \\
\text { of multidrug-resistant } \\
\text { isolates }\end{array}$} \\
\hline $\begin{array}{c}\text { active } \\
\text { substance }\end{array}$ & $\begin{array}{l}\text { antimicrobial } \\
\text { groups }\end{array}$ & & & & \\
\hline 0 & 0 & & 2 & $(8 \%)$ & 0 \\
\hline 1 & 1 & TET & 12 & $(48 \%)$ & \\
\hline 1 & 1 & STR & 1 & $(4 \%)$ & \\
\hline 1 & 1 & RIF & 1 & $(4 \%)$ & \\
\hline 2 & 2 & TET, RIF & 3 & $(12 \%)$ & \\
\hline 2 & 2 & STR, TET & 2 & $(8 \%)$ & \\
\hline 3 & 3 & CLI, STR, TET & 3 & $(12 \%)$ & $4(16 \%)$ \\
\hline 3 & 3 & STR, TET, RIF & 1 & $(4 \%)$ & \\
\hline
\end{tabular}

CLI - clindamycin; STR - streptomycin; TET - tetracycline; RIF - rifampicin.

In contrast to $S$. uberis, only 4 isolates of $S$. dysgalactiae were defined as multiresistant $(16 \%)$. However, the results of antimicrobial susceptibility testing obtained with these pathogens should be assessed cautiously because of the disproportionate number of $S$. uberis $(\mathrm{n}=163)$ isolates compared to $S$. dysgalactiae $(\mathrm{n}=25)$ isolates tested.

\section{Discussion}

This study is one of the first to deal with antimicrobial sensitivity of mastitis pathogens in Czech dairy herds. The largest proportion of antimicrobial use in dairy cows in Europe is attributable to udder health (De Briyne et al., 2014) and although the administration is mainly intramammary and not systemic, their use presents a potential risk of antimicrobial resistance. 
Many of these drugs are also widely used in human medicine, and their routine use in veterinary medicine poses a potential problem. There is a concern that the veterinary use of these drugs could lead to the selection and development of resistant bacteria, which can be dangerous to human health (McEwen and Fedorka-Cray, 2002).

With a $17.4 \%$ prevalence, $S$. uberis was the most frequently isolated mastitis pathogen in other studies (Kalmus et al., 2011; Rüegsegger et al., 2014; Supré et al., 2014) as well as studies from the Czech Republic (Bzdil, 2012). S. uberis was also the most frequently tested mastitis pathogen in the Czech national antibiotic program (SVS ČR, 2017).

There are many international papers dealing with antimicrobial susceptibility of pathogenic streptococci recovered from clinical and subclinical mastitis cases (Guérin-Faublée et al., 2002; Pitkälä et al., 2004; Kalmus et al., 2011; Cameron et al., 2016; Kaczorek et al., 2017). They differ in some respects such as the method of isolate collection, selection of tested antimicrobials, and method of susceptibility testing. The most important criterion for further use of data is related to the interpretation of the results by presenting either summarized results, the frequency of MIC distribution, or susceptibility data based on different national or international breakpoints (Thomas et al., 2015). Large variability between studies makes data comparisons difficult. Furthermore, the differences between the results of antibiotic susceptibility reports from various regions of the world are very often closely related to the consumption of antimicrobials. There are several studies regarding the dependence of antimicrobial resistance on antimicrobial consumption (McEwen and Fedorka-Cray, 2002; Chantziaras et al., 2014; Nedbalcova et al., 2014; EPRUMA, 2017). Therefore, national antibiotic programs in different countries can have a great impact on the occurrence and spread of resistant isolates. All these facts must be considered when studying or comparing results from these studies.

Susceptibility $\geq 95 \%$ of streptococci to beta-lactams (penicillin and/or amoxicillin with clavulanic acid) presented in earlier studies (Guérin-Faublée et al., 2003; Bengtsson et al., 2009; Persson et al., 2011; Rüegsegger et al., 2014; Petrovski et al., 2015; de Jong et al., 2018) applies only to $S$. dysgalactiae isolates in our study. In $S$. uberis, we found only a $65 \%$ susceptibility to penicillin. The $\mathrm{MIC}_{50}$ and $\mathrm{MIC}_{90}$ values of $0.25 \mu \mathrm{g} / \mathrm{mL}$ and $0.5 \mu \mathrm{g} / \mathrm{mL}$, respectively, found in this study were higher than those reported in other studies. Guérin-Faublée et al. (2003) reported an $\mathrm{MIC}_{50}$ of $0.03 \mu \mathrm{g} / \mathrm{mL}$ and an $\mathrm{MIC}_{90}$ of $0.25 \mu \mathrm{g} / \mathrm{mL}$, Pol and Ruegg (2007) reported $0.12 \mu \mathrm{g} /$ $\mathrm{mL}$ and Pitkälä et al. (2004) $0.06 \mu \mathrm{g} / \mathrm{mL}$ for both $\mathrm{MIC}_{50}$ and $\mathrm{MIC}_{90}$. The high value $(35 \%)$ of $S$. uberis isolates with intermediate susceptibility to penicillin found in our study differs from an $89 \%$ susceptibility of S. uberis found predominantly in parts of the Czech Republic within the framework of the voluntary National program of monitoring antimicrobial resistance of pathogens with veterinary importance (SVÚ Jihlava, 2018). However, our result is comparable to results from New Zealand (McDougall et al., 2014) and across Europe (Thomas et al., 2015) where approximately $30 \%$ of the analyzed isolates were classified as intermediate susceptible to the active substance. The isolation of such pathogens could be due to a mutation of penicillinbinding proteins, resulting in a decreased affinity for the drug (Haenni et al., 2010). 
A high percentage of intermediately susceptible strains can present a risk that these pathogens will not respond well to in vivo therapy or may potentially evolve into resistant strains. Increased exposure of animals to antimicrobials or inappropriate dosing protocols (e.g., low doses administered for too short or too long a period) should be considered a significant risk factor for increased bacterial resistance in veterinary medicine (Lees et al., 2008).

According to many researchers, phenotypic resistance to tetracycline is the most common form of resistance in Streptococcus species (Guérin-Faublée et al., 2002; Bengtsson et al., 2009; Ruegg et al., 2015; Crestani et al., 2016; Kaczorek et al., 2017). Our study appears to confirm this; we found the lowest susceptibility and a very high frequency of resistance to tetracycline in S. uberis $(63.2 \%)$ and $S$. dysgalactiae $(60.0 \%)$ isolates. A similarly high occurrence of resistance (S. uberis $(62.1 \%)$ and $S$. dysgalactiae $(63.5 \%)$ ) in the Czech Republic was found in a study monitoring antimicrobial susceptibility between 2015 and 2016 (SVS ČR, 2017). On the other hand, low resistance to tetracycline (12\%) was reported in Sweden (Persson et al., 2011), where the use of tetracycline is significantly less than narrow-spectrum penicillins (De Briyne et al., 2014). The high resistance seen to tetracycline is probably because tetracyclines have been widely used, for many years, to treat a variety of ruminants infections (Kalmus et al., 2011), which is also true in the Czech Republic. It has been shown that many genetic determinants of tetracycline resistance can be actively transferred between bacterial genera and between hosts, both human and animal; as a result, resistance to tetracycline is found in almost all bacterial genera (Aminov et al., 2001).

Because of the intrinsic resistance of streptococci to aminoglycosides (streptomycin), which is a consequence of limited permeability of these antibiotics through the cell wall (Kaczorek et al., 2017), S. uberis isolates were seen to have low susceptibility to streptomycin (47.9\%). Similarly, a low level of susceptibility to streptomycin was confirmed in Croatia with 54.3\% (Leskovec et al., 2015); isolates from the USA and New Zealand (Petrovski et al., 2015) had an even lower susceptibility $(2.2 \%)$.

In the Czech Republic, in addition to amoxicillin products, pirlimycin, linked to lincosamides has recently become popular for the treatment of $S$. uberis-caused mastitis. In our study, we did not directly investigate susceptibility to pirlimycin. Nevertheless, the relatively high resistance $(30.1 \%)$ of $S$. uberis isolates to clindamycin (an antimicrobial used as a class representative when testing lincosamides, e.g., pirlimycin and lincomycin) can pose a certain risk. Similarly, it was reported (Pol and Ruegg, 2007) that in the USA, 24\% of Streptococcus spp. were resistant to pirlimycin. From this point of view, we must be vigilant against the occurrence of resistance to pirlimycin and test the susceptibility of isolates to this antibiotic.

Despite the similarities discussed above, some differences in the frequency of resistant and intermediate isolates between the two main streptococcal species (S. uberis and $S$. dysgalactiae) were found. These were similar to findings reported by Petrovski et al. (2015) and Cameron et al. (2016). Our results demonstrated that most antimicrobials had better in vitro efficacy against $S$. dysgalactiae compared to S. uberis (e.g., penicillin, clindamycin, streptomycin, and rifampicin), whereas fewer 
isolates of $S$. dysgalactiae were susceptible to tetracycline. However, we should consider the great disparity between the numbers of tested $S$. uberis $(\mathrm{n}=163)$ and $S$. dysgalactiae $(\mathrm{n}=25)$ isolates. Based on all our findings, it is advisable to identify pathogens on the species level, rather than the genus level, in order to recommend the best treatment for the respective farm/individual animals.

In our study, multidrug resistance was found in $35.6 \%(67 / 188)$ of the Streptococcus spp. isolates, which was very similar to the results $(34.1 \%)$ from France (Guérin-Faublée et al., 2002), while Chinese researchers reported that $88.9 \%$ of their streptococci isolates ( $S$. agalactiae, $S$. uberis, and $S$. dysgalactiae) were resistant to three or more antimicrobial groups (Ding et al., 2016).

In conclusion, Streptococcus spp. are important mammary gland pathogens, and in our study, they represented $31.1 \%$ of the gram-positive pathogens, the most frequent being Streptococcus uberis, which represented $28.4 \%$ of the gram-positive isolates. A very positive finding was that $S$. uberis and $S$. dysgalactiae were both highly sensitive to amoxicillin-clavulanic acid, trimethoprim-sulfamethoxazole as well as other critically important antimicrobials, under a prudent use regimen, such as ceftiofur, gentamicin, and enrofloxacin. On the other hand, a large percentage of S. uberis were found resistant to tetracycline, streptomycin, and clindamycin. Intermediate susceptibility to rifampicin and penicillin also poses a potential risk of an inadequate therapeutic response. Because of the substantial variation in susceptibility of streptococci, isolated from mastitis cases to tested antimicrobials, it is necessary to use antimicrobials for the treatment of mastitis in a prudent and targeted manner since there are significant differences in the spectra of causative agents and since susceptibilities vary among countries, farms, and investigative periods. These differences also depend on the use of different groups of antimicrobials for the treatment and prevention of all health problems. This is influenced not only by the attitude of veterinarians and farmers but also by national antibiotic policies and by portfolios of authorized and available veterinary products on the respective market. Sensible use of antimicrobials is only one of the building blocks of comprehensive and systematic mastitis control programs and should be used in conjunction with complex dairy herd management, preventive medicine, and biosecurity approaches to keep animals healthy.

\section{Acknowledgments}

This study was supported by the Ministry of Agriculture of the Czech Republic, by grants NAZV QJ1510217 and QJ1910320 and the Ministry of Education, Youth and Sports of the Czech Republic (LO1218). The authors wish to thank Mrs. L. Faldikova, Mr. P. Veater (Bristol, United Kingdom) and Mr. T. Secrest, MSc. for correcting and proofreading the manuscript.

\section{References}

A minov R.I., Garrigues - Je anj e a n N., Macki e R.I. (2001). Molecular ecology of tetracycline resistance: development and validation of primers for detection of tetracycline resistance genes encoding ribosomal protection proteins. Appl. Environ. Microbiol., 67: 22-32. 
Bengtsson B., Ericsson Unnerstad H., Ekman T., Artursson K., Nilsson- Os t M., P e r s s o n Walle r K. (2009). Antimicrobial susceptibility of udder pathogens from cases of acute clinical mastitis in dairy cows. Vet. Microbiol., 136: 142-149.

B ra d l e y A.J. (2002). Bovine mastitis: an evolving disease. Vet. J., 164: 116-128.

Burmańczuk A., Kowalski C., Roliński Z., Zań R., Krasucka D. (2016). Activity of $\beta$-lactam antibiotics against certain microorganisms which cause mastitis in cows. J. Vet. Res., 60: $267-271$.

B z di 1 J. (2004). Bacteriological methods of clinical and pathological material cultivation. Standard Operating Procedure SOP BAK 1/04 (in Czech). State Veterinary Institute Olomouc, Czech Republic, $7 \mathrm{pp}$.

B z d i 1 J. (2012). Prevalence of selected pathogens of mammary gland of cattle in period 2000-2010 (in Czech). Veterinářství, 62: 28-32.

CA-SFM (2018). Comité de l'Antibiogramme de la Société Francaise de Microbiologie - Recommandations Vétérinaries 2018. Paris, France, Société Francaise de Microbiologie, 15 pp.

C a m eron M., S a ab M.,H e id er L., Trenton M c Clure J., R odriguez-L e c o mpte J.C., J a vier S. (2016). Antimicrobial susceptibility patterns of environmental streptococci recovered from bovine milk samples in the Maritime Provinces of Canada. Front Vet Sci., 3: article 79.

Chantziaras I., B oyen F., Callens B., Dew ulf J. (2014). Correlation between veterinary antimicrobials use and antimicrobials resistance in food-producing animals: a report on seven countries. J. Antimicrob. Chemother., 63: 1-8.

CLSI (2013). Performance standards for antimicrobial disk and dilution susceptibility tests for bacteria isolated from animals. Approved Standard, 4th ed. CLSI document VET01-A4. Wayne, PA, USA, Clinical and Laboratory Standards Institute, $70 \mathrm{pp}$.

CLSI (2015). Performance standards for antimicrobial disk and dilution susceptibility tests for bacteria isolated from animals. 3rd ed. CLSI Supplement VET01S. Wayne, PA, USA, Clinical and Laboratory Standards Institute, $117 \mathrm{pp}$.

CLSI (2018). Performance standards for antimicrobial disk and dilution susceptibility tests for bacteria isolated from animals. 4th ed. CLSI supplement VET08. Wayne PA, USA, Clinical and Laboratory Standards Institute, $170 \mathrm{pp}$.

Crestani C., Mancin M., B on amico S., S e galin C., Bus a A., Ros a G., D a 11 ' a va B., Nannoni E., Ostanello F., Barberio A. (2016). Antimicrobial resistance patterns of bovine mastitis pathogens isolated in the north-east of Italy between 2010 and 2014. Large Anim. Rev., 22: 99-106.

De Briyne N., Atkinson J., Pokludová L., Borriello S.P. (2014). Antibiotics used most commonly to treat animals in Europe. Vet. Rec., 175: 325.

de Jong A., El Garch F., Simjee S., Moyaert H., Rose M., Youala M., S i e gwart E. (2018). Monitoring of antimicrobial susceptibility of udder pathogens recovered from cases of clinical mastitis in dairy cows across Europe: VetPath results. Vet. Microbiol., 213: 73-81.

D ing Y., Z h a o J., H e X., Li M., G u a n H., Z h a n g Z., Li P. (2016). Antimicrobial resistance and virulence-related genes of Streptococcus obtained from dairy cows with mastitis in Inner Mongolia, China, Pharm. Biol., 54: 162-167.

EPRUMA (2017). European Platform for the Responsible Use of Medicines in Animals. http://www. epruma.eu/ (Accessed September 20, 2018)

EUCAST (2018). The European Committee on Antimicrobial Susceptibility Testing. Breakpoint tables for interpretation of MICs and zone diameters. Version 8.1, 2018. http://www.eucast.org/clinical breakpoints (Accessed September 29, 2018)

GERMAP 2012 (2014). Antibiotika-Resistenz und -Verbrauch. BVL, PEG, if. http://www.bvl.bund.de/ DE/05_Tierarzneimittel/05_Fachmeldungen/2014/2014_04_10_Fa_germap2012

Guérin-F a u blé e V., Tard y F., B o u veron C., Carret G. (2002). Antimicrobial susceptibility of Streptococcus species isolated from clinical mastitis in dairy cows. Int. J. Antimicrob. Agents, 19: 219-226.

Guérin-F a u blé e V., C a rret G., H o u ff s c h mit t P. (2003). In vitro activity of 10 antimicrobial agents against bacteria isolated from cows with clinical mastitis. Vet. Rec., 152: 466-471.

Ha e n i M., S ar a s E., M a d e c J.Y. (2010). Demonstration of a shift towards penicillin resistance in the Streptococcus uberis population. J. Med. Microbiol., 59: 993-995. 
Ha la s a T., Huijps K., Ø sterås O., Hogeveen H. (2007). Economic effects of bovine mastitis and mastitis management: A review. Vet. Q., 29: 18-31.

Ka c zor ek E., M ała c zew s ka J., Wó j c i k R., Rę k a w ek W., S i w i c ki A.K. (2017). Phenotypic and genotypic antimicrobial susceptibility pattern of Streptococcus spp. isolates from cases of clinical mastitis in dairy cattle in Poland. J. Dairy Sci., 100: 6442-6453.

Kalmus P., A a s mäe B., Kärss in A., Orro T., Kask K. (2011). Udder pathogens and their resistance to antimicrobial agents in dairy cows in Estonia. Acta Vet. Scand., 53: 4.

L e e s P., S v e n d s e n O., Wi u ff C. (2008). Chapter 6. Strategies to minimise the impact of antimicrobial treatment on the selection of resistant bacteria. In: Guide to Antimicrobial Use in Animals 2008, Guardabassi L. (ed.). Blackwell Publishing, Oxford, UK, pp. 77-101.

Leskovec P., Ljoljić D.B., Benić M., Kostelić A., Cvetnić Ž., Antunac N. (2015). Sensitivity of selected mastitis pathogens to antimicrobial agents. Mljekarstvo, 65: 149-158.

M a gi or a k os A.P., S rin ivas a n A., C a r e y R.B., C a r m eli Y., F a la g a s M.E., G is ke C.G.,

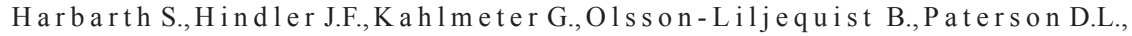
Rice L.B., Stelling J., S truelens M.J., Vat o poulos A., We ber J.T., Monnet D.L. (2011). Multidrugresistant, extensively drug-resistant and andrug-resistant bacteria: An international expert proposal for interim standard definitions for acquired resistance. Clin. Microbiol. Infect., 18: 268-281.

McDougal1 S., Arthur D.G., Bryan M.A., Vermunt J.J., We ir A.M. (2007). Clinical and bacteriological response to treatment of clinical mastitis with one of three intramammary antibiotics. N. Z. Vet. J., 55: 161-170.

M c D o u ga 11 S., H u s s e in H., P e tro v s k i K. (2014). Antimicrobial resistance in Staphylococcus aureus, Streptococcus uberis and Streptococcus dysgalactiae from dairy cows with mastitis. N. Z. Vet. J., 62: 68-76.

McEwen S.A., Fed orka-Cray P.J. (2002). Antimicrobial use and resistance in animals. Clin. Infect. Dis., 34 (Supplement 3): 93-106.

Nedbalcova K., N e chvat a lova K., Pokludova L., Bures J., Kucerova Z., Koutecka L., Hera A. (2014). Resistance to selected beta-lactam antibiotics. Vet. Microbiol., 171: $328-336$.

O live ir a L., H u 11 and C., R u e g g P.L. (2013). Characterization of clinical mastitis occurring in cows on 50 large dairy herds in Wisconsin. J. Dairy Sci., 96: 7538-7549.

O live r S.P., M u rin d a S.E. (2012). Antimicrobial resistance of mastitis pathogens. Vet. Clin. Food Anim. Pract., 28: 165-185.

P e r s s on Y., N y m a n A.K., Grön l und - A n d e r s s o n U. (2011). Etiology and antimicrobial susceptibility of udder pathogens from cases of subclinical mastitis in dairy cows in Sweden. Acta Vet. Scand., 53: 36.

Petrovski K.R., Grinberg A., Williamson N.B., Abdalla M.E., Lopez-Villalobos N., Parkinson T.J., Tu ckerb I.J., R a pn i cki c P. (2015). Susceptibility to antimicrobials of mastitis-causing Staphylococcus aureus, Streptococcus uberis and Str. dysgalactiae from New Zealand and the USA as assessed by the disk diffusion test. Aust. Vet. J., 93: 227-233.

P itkälä A., Haveri M., P yörälä S., Myllys V., Honkanen-Buzalski T. (2004). Bovine mastitis in Finland 2001 - prevalence, distribution of bacteria, and antimicrobial resistance. J. Dairy Sci., 87: 2433-2441.

P o 1 M., Ru e g g P.L. (2007). Relationship between antimicrobial drug usage and antimicrobial susceptibility of gram-positive mastitis pathogens. J. Dairy Sci., 90: 262-273.

P y a tov V., Vrtková I., Knoll A. (2017). Detection of selected antibiotic resistance genes using multiplex PCR assay in mastitis pathogens in the Czech Republic. Acta Vet. Brno, 86: 167-174.

Ru e g g P.L., O live ir a L., Jin W., O kw u mabua O. (2015). Phenotypic antimicrobial susceptibility and occurrence of selected resistance genes in gram-positive mastitis pathogens isolated from Wisconsin dairy cows. J. Dairy Sci., 98: 1-14.

Rü egs e gger F., Ruf J., Ts chuor A., Sigrist Y., Ross k opf M., Hässig M. (2014). Antimicrobial susceptibility of mastitis pathogens of dairy cows in Switzerland. Schweiz. Arch. Tierheilk., 156: 483-488.

S chwarz S., Silley P., Simjee S., Woodford N., van Duijkeren E., Johnson A.P., $\mathrm{G}$ a a s $\mathrm{tr}$ a W. (2010). Assessing the antimicrobial susceptibility of bacteria obtained from animals. Vet. Microbiol., 141: 1-4. 
Supré K., Lommelen K., de Meulemeester L. (2014). Antimicrobial susceptibility and distribution of inhibition zone diameters of bovine mastitis pathogens in Flanders, Belgium. Vet. Microbiol., 171: 374-381.

SVA (2018) Swedres-Svarm 2017. Consumption of antibiotics and occurrence of resistance in Sweden. https:/www.sva.se/globalassets/redesign2011/pdf/om_sva/publikationer/swedres_svarm2017.pdf (Accessed September 20, 2018).

SVS ČR (2017). National programme of monitoring antimicrobial resistance of pathogens with veterinary importance (in Czech). Informační bulletin 4/2017. https://www.svscr.cz/narodni-programsledovani-rezistenci-k-antimikrobikum-u-veterinarne. (Accessed September 20, 2018).

SVÚ Jihlava (2018). National programme of monitoring antimicrobial resistance of pathogens with veterinary importance (in Czech). https://www.svujihlava.cz/intranet/publikace/Zprava_cast_I_ NAP 2017.pdf (Accessed September 20, 2018).

Š tro m e ro vá N. (2013). Species identification of bacteria by MALDI - TOF method. Standard Operating Procedure SOP BAK 1/10 (in Czech). State Veterinary Institute Olomouc, Czech Republic, $7 \mathrm{pp}$.

Thomas V., de Jong A., Moyaert H., Simjee S., El Garch F., Morrissey I., Mar i o n H., Vallé M. (2015). Antimicrobial susceptibility monitoring of mastitis pathogens isolated from acute cases of clinical mastitis in dairy cows across Europe: VetPath results. Int. J. Antimicrob. Agents, 46: 13-20.

Wat $\mathrm{s}$ J.L. (1988). Etiological agents of bovine mastitis. Vet. Microbiol., 16: 41-66.

Received: 24 X 2018

Accepted: 11 II 2019 